\title{
Progressive Multifocal Leukoencephalopathy Associated with Pulmonary Tuberculosis in an Immuno-Compromised Indian Patient
}

\section{Krishna Pandey ${ }^{1 \#, ~ D h a r m e n d r a ~ S i n g h #, ~ V i d y a n a n d ~ R a b i ~ D a s ~}{ }^{1}$, Sanjiva Bimal ${ }^{3}$, Bipin K. Singh ${ }^{4}$ and Pradeep Das*2}

${ }^{1}$ Department of Clinical Medicine, Rajendra Memorial Research Institute of Medical Sciences (Indian Council of Medical Research), Agamkuan, Patna, Bihar, India ${ }^{2}$ Department of Molecular Biology \& Tuberculosis Division, Rajendra Memorial Research Institute of Medical Sciences (Indian Council of Medical Research), Agamkuan, Patna, Bihar, India

${ }^{3}$ Department of Immunology, Rajendra Memorial Research Institute of Medical Sciences (Indian Council of Medical Research), Agamkuan, Patna-800 007, Bihar, India ${ }^{4}$ Department of Antiretroviral Treatment Center, Rajendra Memorial Research Institute of Medical Sciences (Indian Council of Medical Research), Agamkuan, Patna-800 007, Bihar, India

\#Krishna Pandey and Dharmendra Singh have equal contributions as first author to the manuscript

\begin{abstract}
We present here a case of progressive visual loss and convulsions in a 45 year old male immuno-compromised patient with pulmonary tuberculosis. He was subsequently diagnosed as Progressive Multifocal Leukoencephalopathy $(\mathrm{PML})$ based on Magnetic Resonance Imaging, cerebrospinal fluid and clinical findings.
\end{abstract}

Keywords: PML; HIV; AIDS; Tuberculosis

\section{Introduction}

Progressive Multifocal Leukoencephalopathy (PML) is a rare syndrome which occurs in immune-compromised patients in about 2 to $5 \%$ of the cases. It occurs almost exclusively in people with severe immune deficiency, such as transplant patients on immunosuppressive medications, those on certain kinds of chemotherapy, receiving natalizumab for multiple sclerosis, on long-term efalizumab for psoriasis, brentuximab for Hodgkin's Lymphoma or those with Acquired Immuno Deficiency Syndrome (AIDS) [1-3]. The causative agent of the disease JC virus belongs to papovavirus family which has been divided into polyomavirus and papillomavirus. JC Virus is a Polyomavirus (JCPyV). Tuberculosis is another disease of major public health problem in India. Both these diseases namely HIV and tuberculosis are immune suppressive in nature. In this unique case report we describe an Indian patient who had HIV1 infection in association with PML and pulmonary tuberculosis.

\section{Case Report}

A 45 years old male patient presented to our outpatient clinic in December 2012 with complaints of progressive visual loss in both eyes, headache, difficulty in walking, loss of memory and repeated generalised tonic-clonic seizures. He was a driver by profession and had studied up to undergraduate level. On close questioning he revealed contact with multiple commercial sex workers. He was an alcoholic and smoked 2 cigarettes a day. He also had cough with haemoptysis (small amount) and low grade fever $\left(100^{\circ} \mathrm{F} / 38^{\circ} \mathrm{C}\right)$ at the time of presentation. He had loose motions 3 to 4 times per day for the past 3 weeks and candidiasis of the tongue. Pulse rate was $100 / \mathrm{min}$, respiration rate $20 /$ min, blood pressure $120 / 86 \mathrm{mmHg}$ in the left upper limb in supine posture. Weight of the patient was $56 \mathrm{~kg}$ and height $165 \mathrm{~cm}$. Chest examinations revealed coarse crepitations bilaterally more marked in the right upper zone. Cardiovascular system examination was normal and so was the abdominal examination. Clinical examination of the eye revealed figure counting at about 2 feet. Other neurological examination revealed bilateral extensor planters. The Mini Mental Status Examination (MMSE) had a score of 20/30 thereby indicating features of moderate dementia. An ophthalmologist confirmed bilateral optic atrophy. The patient had dysmetria and a staggering gait but no hemiplegia. He had slurring of speech. Laboratory investigations revealed normal liver, renal function tests and complete blood count except for a haemolglobin level of $9.0 \mathrm{gm} / 100 \mathrm{ml}$. HIV 1 was positive by two rapid kits and further confirmed by Enzyme Linked Immuno Sorbent Assay (ELISA) as per National AIDS Control Organisation (NACO) of India guidelines. The $\mathrm{CD}_{4}$ count of the patient was $103 / \mu \mathrm{l}$. Plasma viral load was $>10000$ copies/ml. Chest X-Ray postero-anterior view showed evidence of bilateral infiltrations in both the lungs more marked on the right (Figure 1). Most of the above clinical findings were attributable to HIV infection.

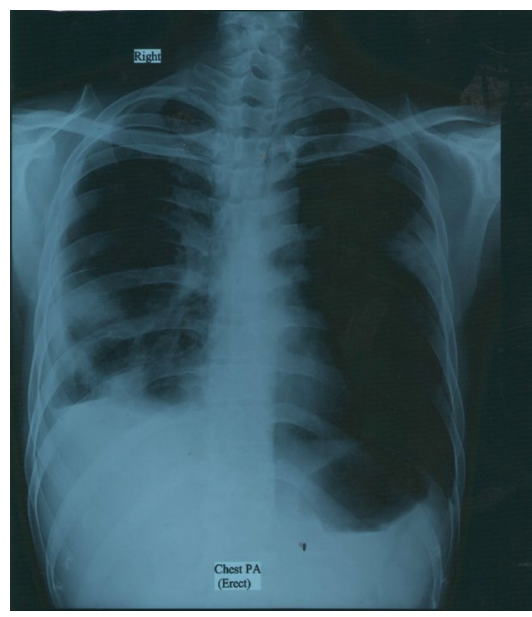

Figure 1: X-ray chest PA view showing patchy non-homogenous opacity more marked in the right mid and lower zone suggestive of tuberculosis infection.

*Corresponding author: Pradeep Das, Scientist-G \& Director, Department of Clinical Medicine, Rajendra Memorial Research Institute of Medical Sciences (Indian Council of Medical Research), Agamkuan, Patna-800 007, Bihar, India, Tel: +919431012380, E-mail: drpradeep.das@gmail.com

Received July 17, 2013; Accepted August 28, 2013; Published August 31, 2013

Citation: Pandey K, Singh D, Das VR, Bimal S, Singh BK, et al. (2013) Progressive Multifocal Leukoencephalopathy Associated with Pulmonary Tuberculosis in an Immuno-Compromised Indian Patient. J AIDS Clin Res 4: 241. doi: 10.4172/21556113.1000241

Copyright: ( 2013 Pandey K, et al. This is an open-access article distributed under the terms of the Creative Commons Attribution License, which permits unrestricted use, distribution, and reproduction in any medium, provided the original author and source are credited. 
Two sputum samples, one spot and one overnight were collected in sterile McCartney's bottles. Sputa were decontaminated by modified Petroff's method and then subjected to microbiological examination by Ziehl-Neelsen technique for acid fast bacilli and culture on solid Lowenstein-Jensen (L-J) medium for mycobacterium tuberculosis. The drug susceptibility test (DST) was performed by using a highthroughput, $1 \%$ proportional absolute concentration method of four first line anti-tuberculosis drugs namely Isoniazid $(0.2 \mu \mathrm{g} / \mathrm{ml})$, Rifampicin $(40 \mu \mathrm{g} / \mathrm{ml})$, Streptomycin $(4 \mu \mathrm{g} / \mathrm{ml})$, and Pyrazinamide $(200$ $\mu \mathrm{g} / \mathrm{ml}$ ) on L-J medium according to WHO guidelines [4]. The culture was sensitive to above mentioned four first line anti-tuberculosis drugs. Mycobacterium tuberculosis was identified by its special eugenic growth, colony morphology and biochemical tests such as niacin accumulation, nitrate reduction, and insertion sequence (IS6110) by polymerase chain reaction (PCR) $[5,6]$. This was confirmed with $M$. tuberculosis $\left(\mathrm{H}_{37} \mathrm{Rv}\right)$ reference strain. Streptomycin was added as the patient had visual difficulty thereby avoiding Ethambutol which can lead to retro bulbar neuritis.

Electroencephalogram showed evidence of diffuse slowing. A cerebrospinal fluid (CSF) examination was done and it was normal. However, PCR was positive for JC virus with a value of $>3.64$ log copies/ $\mathrm{ml}$ [7]. Computerised tomography (CT) scan demonstrated multiple areas of non-enhancing lesions in white matter. In the magnetic resonance imaging (MRI) $\mathrm{T}_{1}$ and $\mathrm{T}_{2}$ weighted images showed increased signal intensity of the temporo-occipital white matter with relative cortical sparing (Figure 2 and 3 ).

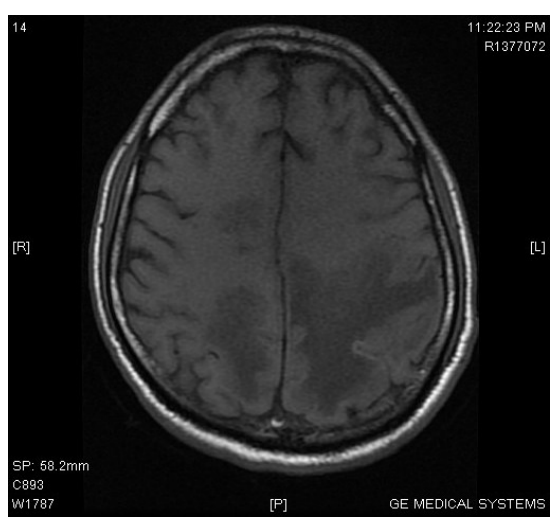

Figure 2: $T_{1}$ weighted axial MRI of the brain showing increased signal intensity with lesions bilateral occipito temporal and "parietal" regions.

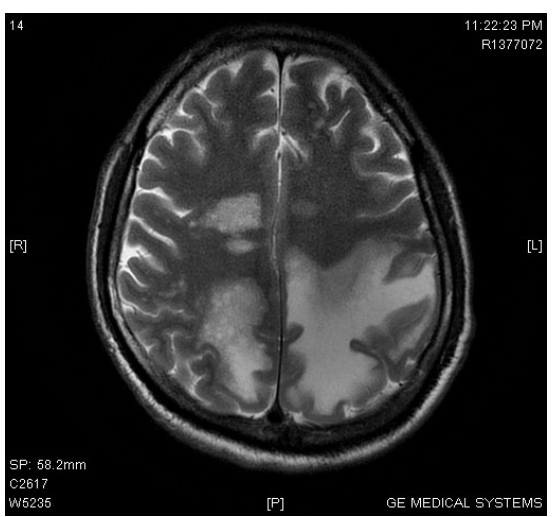

Figure 3: $T_{2}$ weighted axial MRI of the brain showing increased signal intensity with lucencies bilateral occipito temporal and "parietal" regions.
Considering the clinical as well as the CSF, CT and MRI findings a diagnosis of PML with pulmonary tuberculosis in an immunocompromised patient was made (WHO clinical stage IV). The patient was continued on anti-tuberculosis therapy with oral rifampicin (450 $\mathrm{mg}$ ), isoniazid $(300 \mathrm{mg})$, pyrazinamide $(1500 \mathrm{mg})$ with pyridoxine $20 \mathrm{mg} /$ day and streptomycin $(1000 \mathrm{mg})$ intra muscular. Tablet Moxifloxacin ( $400 \mathrm{mg} /$ day) was added due to the fact that it has shown a very good response when used in combination with the first line drugs [8]. After 2 months only rifampicin and isoniazid was continued for a further period of four months. He was started on phenytoin sodium (300 mg/day) at bedtime for seizures. Antiretroviral therapy (ART) was initiated with Zidovudine (300 mg) twice daily, Lamivudine (150 $\mathrm{mg}$ ) twice daily and Efavirenz (600 mg) once daily at bedtime orally, two weeks after initiation of antituberculous therapy. Efavirenz has less drug interaction with Rifampicin as compared to Nevirapine $[9,10]$. Candidiasis was treated with tablet fluconazole $(150 \mathrm{mg})$ once daily orally. Tablet memantine (NMDA receptor blocker) and donepezil (acetyl cholinesterase inhibitor) combination was added for memory loss. The patient is being monitored and is improving slowly. He has been followed up to six months; $\mathrm{CD}_{4}$ count has increased to $152 / \mu \mathrm{l}$ and weight has increased to $60 \mathrm{~kg}$. Phenytoin sodium, ART, memantine and donepezil are being continued. Signed informed consent was obtained from the patient prior to initiation of investigations and treatment.

\section{Discussion}

PML is difficult to diagnose and treat particularly in a poor country like India. The main basis of diagnosis is a high level of suspicion in an immunocompromised person. The confirmation of diagnosis can be made by classical CT, MRI findings as well as by the demonstration of papovavirus (JC virus) by brain biopsy or PCR from CSF in a HIV positive patient. The PCR for JCV is not specified. While diagnostic PCR is somewhat standard technique, there is no widely available commercial kit for JCV and choice of primers/probes and amplification conditions are important. The simian virus (SV) 40 and BK virus (BKV) share significant homology with JCV and the wrong choice of primers could amplify non-specifically. Equally controls in this assay are extremely important since this is the final diagnostic criteria for PML $[11,12]$. Eosinophilic intracytoplasmic inclusion bodies are seen in the oligodendroglial cells at the periphery of the lesions in PML. Electron microscopy studies have shown these inclusion bodies to be composed of papovavirus cells. There is multifocal demyelination in the cerebellum, brain stem and spinal cord white matter with perivascular infiltration. The clinical features include visual loss, convulsions, hemiplegia, cranial nerve palsies, focal neurological deficits, ataxia, convulsions and progressive dementia [13]. Bad prognostic indicators include a $\mathrm{CD}_{4}$ count of less than $100 / \mu \mathrm{L}$ associated with other opportunistic infections [14]. There is no effective treatment for PML but with the advent of ART, the prognosis may be better [15-17]. Cidofovir and camptothecin are two new drugs which are being used in controlled clinical studies. Camptothecin, an alkaloid cytostatic inhibits topoisomerase 1 which is required for DNA of JC Virus replication [18]. Cidofovir, a nucleotide analogue is used for treatment of cytomegalo virus (CMV) has also been found to be effective in a few patients but can lead to nephro toxicity [19]. However in a retrospective analysis of 35 patients it was not found to be as effective and is no longer used for the treatment of PML [20]. In the recent years 5-HT2 inhibitors/ serotonin receptor antagonists have been proposed for PML treatment [21]. Experimental case studies for some agents such as risperidone and mirtazapine, serotonergic receptor blockers are being tried [22,23]. The best treatment option at present is focused on antiretroviral agents like Zidovudine, Emtricitabine, Abacavir, Nevirapine and Lopinavir. 
Citation: Pandey K, Singh D, Das VR, Bimal S, Singh BK, et al. (2013) Progressive Multifocal Leukoencephalopathy Associated with Pulmonary Tuberculosis in an Immuno-Compromised Indian Patient. J AIDS Clin Res 4: 241. doi: 10.4172/2155-6113.1000241

Currently as per NACO guidelines Protease inhibitors are regarded as the second line treatment for HIV. No prophylaxis is available. As per the previous records death usually occurs within 9 to 12 months in $80 \%$ of the cases but again it depends on the time of initiation of ART and the viral load $[24,25]$. A previous study determined JCV DNA loads in patients with HIV and tuberculosis but did not present MRI findings [26]. This case report is of special interest because it uses both PCR and MRI to diagnose PML in a HIV positive patient with tuberculosis.

\section{Acknowledgements}

The authors are extremely thankful to Dr. Vishwa Mohan Katoch, Secretary, Department of Health Research, Ministry of Health and Family Welfare Government of India and Director General, Indian Council of Medical Research (ICMR), New Delhi, for the establishment of Tuberculosis Research (MDR/XDR) and Antiretroviral Therapy Center at Rajendra Memorial Research Institute of Medical Sciences (ICMR), Patna, Bihar, India

\section{References}

1. Kean JM, Rao S, Wang M, Garcea RL (2009) Seroepidemiology of human polyomaviruses. PLoS Pathog 5: e1000363.

2. Kappos L, Bates D, Edan G, Eraksoy M, Garcia-Merino A, et al. (2011) Natalizumab treatment for multiple sclerosis: updated recommendations for patient selection and monitoring. Lancet neurol 10: 745-758.

3. Mateen FJ, Muralidharan R, Carone M, van de Beek D, Harrison DM, et al. (2011) Progressive multifocal leukoencephalopathy in transplant recipients. Ann Neurol 70: 305-322.

4. Abdel M, Laszlo A, Raviglione M, Rieder H, Espinal M, et al. (2003) Guidelines for surveillence of drug resistance in tuberculosis. World Health Organisation, Geneva.

5. Beerbal Sachan AS, Singh D, Gupta RK, Chauhan DS, Sharma VD, et al. (1999) Application of polymerase chain reaction (PCR) for detection of M. Tuberculosis in sputum specimens. Ind J Tub 46: 235-238.

6. Katoch VM, Parashar D, Chauhan DS, Singh D, Sharma VD, et al. (2007) Rapid identification of mycobacteria by gene amplification restriction analysis technique targeting 16S-23S ribosomal RNA internal transcribed spacer \& flanking region. Indian J Med Res 2: 155-162.

7. Bossolasco S, Calori G, Moretti F, Boschini A, Bertelli D, et al. (2005) Prognostic significance of JC virus DNA levels in cerebrospinal fluid of patients with HIVassociated progressive multifocal leukoencephalopathy. Clin Infect Dis 40: 738744

8. Pranger $A D$, van Altena $R$, Aarnoutse RE, van Soolingen $D$, Uges $D R$, et al. (2011) Evaluation of moxifloxacin for the treatment of tuberculosis: 3 years of experience. Eur Respir J 38: 888-894.

9. Manosuthi W, Sungkanuparph S, Tantanathip P, Lueangniyomkul A, Mankatitham W, et al. (2009) A randomized trial comparing plasma drug concentrations and efficacies between 2 nonnucleoside reverse-transcriptase inhibitor-based regimens in HIV-infected patients receiving rifampicin: the N2R Study. Clin Infect Dis 48: 1752-1579.

10. Swaminathan S, Padmapriyadarsini C, Venkatesan P, Narendran G, Ramesh Kumar S, et al. (2011) Efficacy and safety of once-daily nevirapine- or efavirenzbased antiretroviral therapy in HIV-associated tuberculosis: a randomized clinical trial. Clin Infect Dis 53: 716-724.

11. Egli A, Infanti L, Dumoulin A, Buser A, Samaridis J, et al. (2009) Prevalence of polyomavirus BK and JC infection and replication in 400 healthy blood donors. $\mathrm{J}$ Infect Dis 199: 837-846.

12. Li RM, Mannon RB, Kleiner D, Tsokos M, Bynum M, et al. (2002) BK virus and SV40 co-infection in polyomavirus nephropathy. Transplantation 74: $1497-$ 1504.
13. Berenguer J, Miralles P, Arrizabalaga J, Ribera E, Dronda F, et al. (2003) Clinical course and prognostic factors of progressive multifocal leukoencephalopathy in patients treated with highly active antiretroviral therapy. Clin Infect Dis 36 1047-1052.

14. Berger JR, Levy RM, Flomenhoft D, Dobbs M (1998) Predictive factors for prolonged survival in acquired immunodeficiency syndrome-associated progressive multifocal leukoencephalopathy. Ann Neurol 44: 341-349.

15. Clifford DB, Yiannoutsos C, Glicksman M, Simpson DM, Singer EJ, et al. (1999) HAART improves prognosis in HIV-associated progressive multifocal leukoencephalopathy. Neurology 52: 623-625.

16. Engsig FN, Hansen AB, Omland LH, Kronborg G, Gerstoft J, et al. (2009) Incidence, clinical presentation, and outcome of progressive multifocal leukoencephalopathy in HIV-infected patients during the highly active antiretroviral therapy era: a nationwide cohort study. J Infect Dis 199: 77-83.

17. Gasnault J, Taoufik Y, Goujard C, Kousignian P, Abbed K, et al. (1999) Prolonged survival without neurological improvement in patients with AIDSrelated progressive multifocal leukoencephalopathy on potent combined antiretroviral therapy. J Neurovirol 5: 421-429.

18. O'Reilly S (1997) Efficacy of camptothecin in progressive multifocal leucoencephalopathy. Lancet 350: 291.

19. Kraemer C, Evers S, Nolting T, Arendt G, Husstedt IW (2008) Cidofovir in combination with HAART and survival in AIDS-associated progressive multifocal leukoencephalopathy. J Neurol 255: 526-531.

20. De Luca A, Ammassari A, Pezzotti P, Cinque P, Gasnault J, et al. (2008) Cidofovir in addition to antiretroviral treatment is not effective for AIDSassociated progressive multifocal leukoencephalopathy: a multicohort analysis. AIDS 22: 1759-1767

21. Focosi D, Kast RE, Maggi F, Lauria G, Ceccherini-Nelli L, et al. (2008) 5-HT2a inhibitors for progressive multifocal leukoencephalopathy: old drugs for an old disease. J Infect Dis 197: 328.

22. Focosi D, Kast RE, Maggi F, Ceccherini-Nelli L, Petrini M (2007) Risperidoneinduced reduction in $\mathrm{JC}$ viruria as a surrogate marker for efficacy against progressive multifocal leukoencephalopathy and hemorrhagic cystitis. J Clin Virol 39: 63-64.

23. Cettomai D, McArthur JC (2009) Mirtazapine use in human immunodeficiency virus-infected patients with progressive multifocal leukoencephalopathy. Arch Neurol 66: 255-258.

24. Marzocchetti A, Tompkins T, Clifford DB, Gandhi RT, Kesari S, et al. (2009) Determinants of survival in progressive multifocal leukoencephalopathy. Neurology 73: 1551-1558.

25. Wyen C, Hoffmann C, Schmeisser N, Wöhrmann A, Qurishi N, et al. (2004) Progressive multifocal leukencephalopathy in patients on highly active antiretroviral therapy: survival and risk factors of death. J Acquir Immune Defic Syndr 37: 1263-1268.

26. Kannangai R, Sachithanandham J, Mahadevan A, Abraham AM, Sridharan G, et al. (2013) Association of neurotropic viruses in HIV-infected individuals who died of secondary complications of tuberculosis, cryptococcosis, or toxoplasmosis in South India. J Clin Microbiol 51: 1022-1025. 